\title{
Wideband Microstrip antenna for detection of solvents in water
}

\author{
Rajshri Mahajan ${ }^{1,2}$ and Vibha Vyas $^{3}$ \\ ${ }^{1}$ College of Engineering, Pune \\ ${ }^{2} \mathrm{COEP}$ \\ ${ }^{3}$ College of Engineering Pune
}

May 5, 2020

\begin{abstract}
The paper presents a novel technique to detect the solvents in water like sugar, salt, and its combination using a wideband CPW fed microstrip antenna with periodic EBG ground structure. The antenna is designed and fabricated to operates at the bandwidth of $3 \mathrm{GHz}$ with a stable gain of $9 \mathrm{dBi}$ maintaining $\mathrm{VSWR}<2$. The uniquely designed antenna works as a sensor in its near field to sense the solvents in water in terms of resonant frequency and reflection method in wider bandwidth. The technique also detects the changes in the temperature of the soft drinks as a function of reflection characteristics. This technique will be useful for finding the percentage of solvents in soft drinks before consumption. The sensing technique is without physical contact with the solution and chemical process. Therefore it is a healthy way to find the ingredients in solutions like soft drinks. The technique will be useful to the food regulation boards to limit the contents of beverages and cold drinks.
\end{abstract}

\section{Hosted file}

Wideband Microstrip antenna for detection of solvents in water.pdf available at https: //authorea.com/users/295822/articles/424710-wideband-microstrip-antenna-for-detectionof-solvents-in-water 